\title{
Aerodynamics of the Cupped Wings during Peregrine Falcon's Diving Flight
}

\author{
Benjamin Ponitz, Michael Triep, Christoph Brücker \\ Institute of Mechanics and Fluid Dynamics, TU Bergakademie Freiberg, Freiberg, Germany \\ Email: Benjamin.Ponitz@imfd.tu-freiberg.de, Michael.Triep@imfd.tu-freiberg.de
}

Received 1 October 2014; revised 31 October 2014; accepted 28 November 2014

Copyright (C) 2014 by authors and Scientific Research Publishing Inc.

This work is licensed under the Creative Commons Attribution International License (CC BY). http://creativecommons.org/licenses/by/4.0/

(c) (i) Open Access

\begin{abstract}
During a dive peregrine falcons can reach velocities of more than $320 \mathrm{~km} / \mathrm{h}$ and makes themselves the fastest animals in the world. The aerodynamic mechanisms involved are not fully understood yet and the search for a conclusive answer to this fact motivates the three-dimensional (3-D) flow study. Especially the cupped wing configuration which is a unique feature of the wing shape in falcon peregrine dive is our focus herein. In particular, the flow in the gap between the main body and the cupped wing is studied to understand how this flow interacts with the body and to what extend it affects the integral forces of lift and drag. Characteristic shapes of the wings while diving are studied with regard to their aerodynamics using computational fluid dynamics (CFD). The results of the numerical simulations via ICEM CFD and OpenFOAM show predominant flow structures around the body surface and in the wake of the falcon model such as a pair of body vortices and tip vortices. The drag for the cupped wing profile is reduced in relation to the configuration of opened wings (without cupped-like profile) while lift is increased. The purpose of this study is primarily the basic research of the aerodynamic mechanisms during the falcon's diving flight. The results could be important for maintaining good maneuverability at high speeds in the aviation sector.
\end{abstract}

\section{Keywords}

Peregrine Falcon, Aerodynamics, Cupped Wings, CFD

\section{Introduction}

The peregrine falcon (Falco peregrinus) is one of the world's fastest birds. During horizontal flight, it reaches velocities of up to $150 \mathrm{~km} / \mathrm{h}$ ([1] [2]) and even more than $320 \mathrm{~km} / \mathrm{h}$ when nose-diving to attack its bird prey (e.g. [3]-[10]). Nearly all bird species can alter the shape of their wings and thus they can change their aerodynamic properties [11] [12], a concept known as "morphing wing" [13]. During a dive, peregrines also alter the shape of 
their wings; while accelerating, they move them closer and closer to their body [10]. Several body shapes can be described as a classical diamond shape of the wings followed by a tight vertical tuck with a cupped-like profile of the frontal wing parts [10] [14]-[16]. Only at top velocities (up to at least $320 \mathrm{~km} / \mathrm{h}$ ) peregrines build a wrap dive vacuum pack, i.e. the wings are completely folded against the elongated body [17]. Peregrines are not only extremely fast flyers but also maintain remarkable maneuverability at high speeds. For instance, during courtship behavior they often change their flight path at the end of a dive, i.e. they turn from a vertical dive into a steep climb. This suggests that peregrines are exposed to high mechanical loads.

Although the nose-diving flight of peregrines has been investigated for numerous times, exact numerical flow simulations have not been carried out. Therefore, we investigated different wing configurations (opened wings and cupped wings extension [9]) of the peregrine falcon during diving flight. Both geometries are gained from a previous study by Ponitz et al. (2014) [18] at maximum diving velocities from a dam wall dive. The present study investigates the influence of the geometry change of the extended cupped wings configuration via numerical simulations. The results show that the cupped wings reduce both form and induced drag, while increasing the lift coefficient. This shows how fine the bird can tune the body forces by morphing the wing shape in diving flight conditions.

\section{Materials and Methods}

\subsection{Geometries and Models of the Falcon}

\subsubsection{Dam Wall Diving Flights of Real Falcons}

The numerical simulation in this study is based on the specific diving flight condition which is gained from a previous study by [18]. A peregrine falcon was trained to dive from a dam wall and the dive was captured with a stereo high-speed camera system to reconstruct the 3-D flight path. Furthermore, a camera equipped with 400 $\mathrm{mm}$ zoom lenses was used to gain detail studies of the falcon body geometry. The region of interest shows three flight phases: (1) acceleration/diving phase, (2) transient phase with roughly constant speed and (3) deceleration phase. A maximum dive speed of $22.5 \mathrm{~m} / \mathrm{s}$ was derived from the flight trajectory at flight phase (2). During the dive two significant body geometries are determined around the transient flight phase (2): one configuration without cupped wings (hereinafter called "opened wings") and one configuration with cupped wings [9] (see Figure 1). For the investigated flight situation an angle of attack $\alpha=5^{\circ}$ was determined for the equilibrium condition at the maximum diving speed of $22.5 \mathrm{~m} / \mathrm{s}$. For this flight situation wings remain stationary and do not flap.

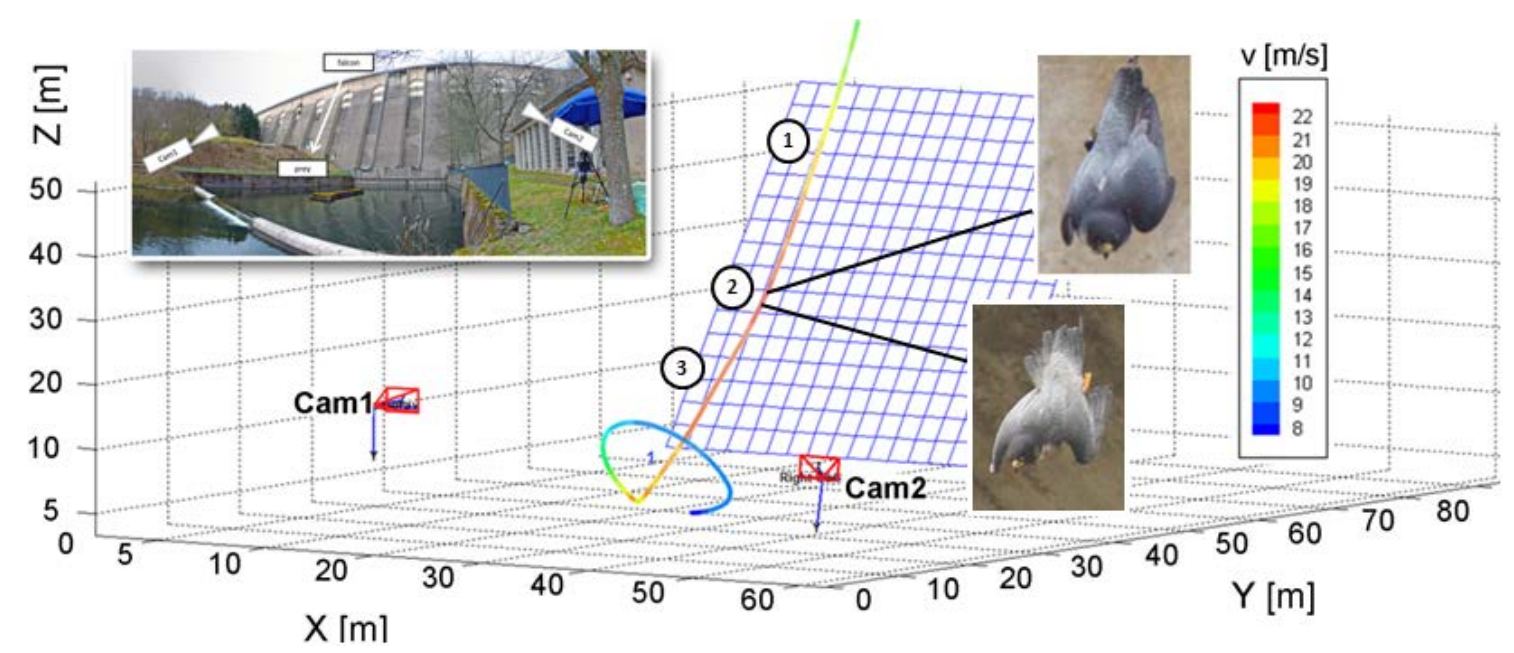

Figure 1. 3-D flight path and detailed body geometries of the falcon's dive from dam wall Olef-Talsperre, Germany. The trajectory is color-coded with the flight velocity magnitude (red color: higher velocities). The region of interest shows three flight phases: (1) acceleration/diving phase, (2) transient phase with roughly constant speed and (3) deceleration phase. Maximum velocity during the dive was $22.5 \mathrm{~m} / \mathrm{s}$ at flight phase (2). For this transient phase two specific configurations (opened wings and cupped wings) were obtained. An angle of attack $\alpha=5^{\circ}$ was determined for the equilibrium condition [18]. 


\subsubsection{Generation of the Models}

A life-sized model was built for both configurations, opened wings and cupped wings. Thus, we used the stuffed body of a female peregrine falcon and manually modified its wings until every body shape matched to the geometries of the falcon during dive from the dam wall (see Figure 1). The main part of the body for both configurations is identical. Only the tips of the wings are modified by a kind of winglets extension (cupped wings). Each modified body was fixated and subsequently scanned to acquire its 3-D surface contours (see Figure 2). In a further step, a one-to-one polyvinyl chloride (PVC) model was fabricated by laser sintering process using the acquired 3-D data. The experimental data from wind-tunnel test on this PVC falcon model is needed to evaluate the numerical simulations. Details of the aerodynamic relevant surface areas are given in Table 1.

\subsection{Experimental Set-Up}

For evaluating the numerical model the flow around the life-size PVC model was measured in a type Göttingenwind-tunnel. A force-balance delivered experimental data of the lift and drag forces of the identical model geometry. Hence, results of the wind-tunnel tests can be compared with numerical simulation results of lift and drag coefficients. The experimental set-up is depicted in Figure 3.

\subsection{Numerical Set-Up}

The numerical flow simulations of the falcon allow visualizing flow regions that are difficult to access by experimental methods. Furthermore, they enable to show distributions, for example, of the wall shear stress or pressure in order to identify hot spots, and most important for the present work, the exact determination of quantities like the $\lambda_{2}$ vortex criterion of the flow field. In the present study, the three-dimensional CAD model of the falcon is transferred into a computational unstructured grid using a grid generation tool ICEM CFD 14.5 (ANSYS, Inc., Canonsburg, PA, USA). The computational domain as marked in Figure 4 includes the inflow region, the falcon region, and the downstream wake region of the flow.

Special attention was paid to the meshing of the falcon. Refinements toward near-wall regions were taken into consideration. The grid consists in total of 6.5 million unstructured tetrahedron cells and 1.5 million prism cells on the falcon surface. A mesh independency check for the results of lift and drag coefficients was done for up to 10 million cells. Simulation stability was investigated in respect to different grid parameters and following settings leads to stable results: The height of the first prisms layer on the falcon surface is set to $0.1 \mathrm{~mm}\left(y^{+}=0.2\right)$ with a growth factor of 1.10 for the following layer perpendicular to the wall and a total number of 10 layers

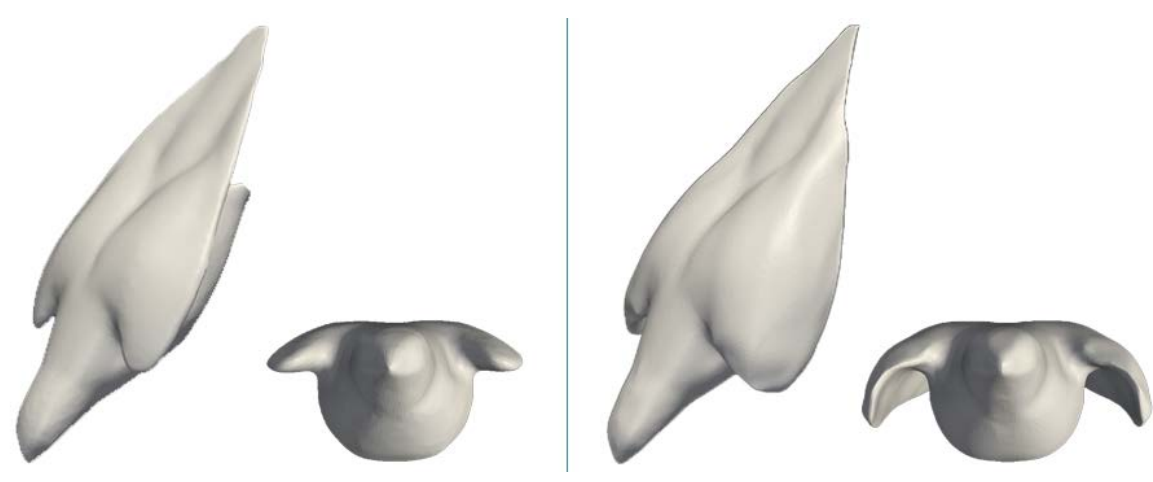

Figure 2. Computer aided design (CAD) falcon models: opened wingshape (left) and cupped wing shape (right).

Table 1. Reference areas of the falcon modelswith opened wings and cupped wings.

\begin{tabular}{ccc}
\hline & \multicolumn{2}{c}{ Reference area } \\
\cline { 2 - 3 } Aspect view & Opened wings & Cupped wings \\
\hline Top-view projection area & $A_{\text {ref,opened,top }}=0.0411 \mathrm{~m}^{2}$ & $A_{\text {ref,cupped,top }}=0.0421 \mathrm{~m}^{2}$ \\
Frontal projection area & $A_{\text {ref,opened,front }}=0.0123 \mathrm{~m}^{2}$ & $A_{\text {ref,cupped,front }}=0.0139 \mathrm{~m}^{2}$ \\
\hline
\end{tabular}




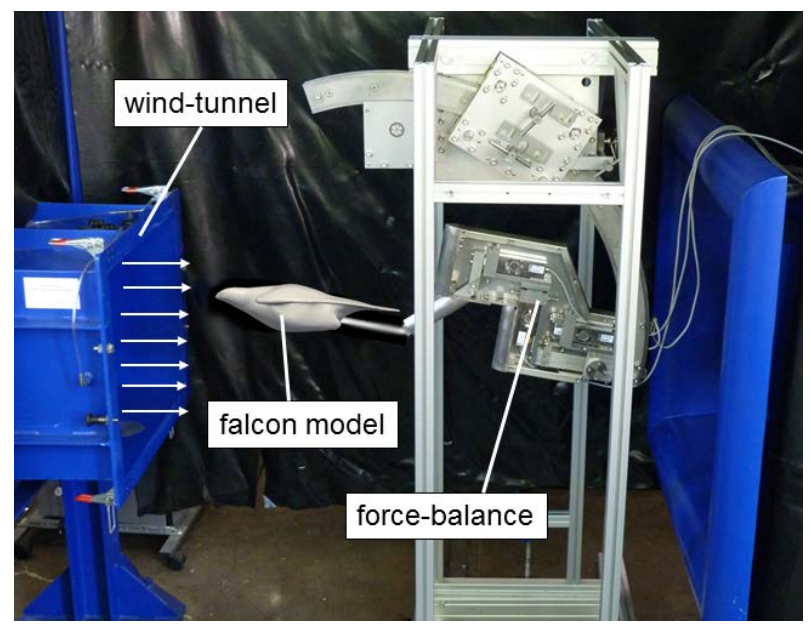

Figure 3. PVC falcon model and force-balance in the windtunnel [18].

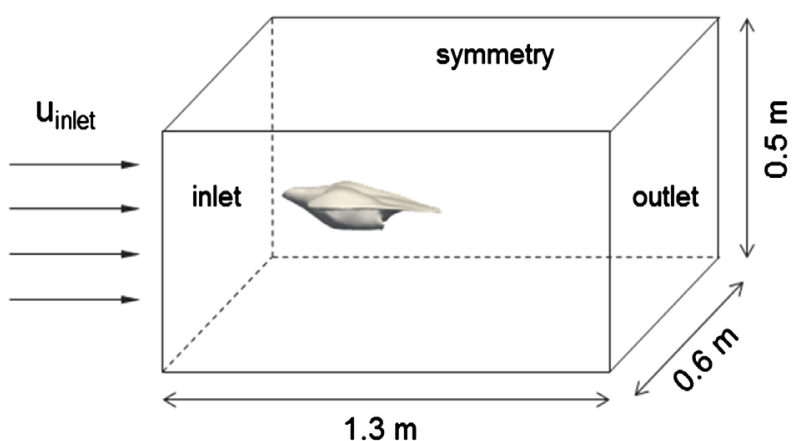

Figure 4. Numerical model dimensions and boundary conditions.

(Figure 5). For these simulation parameters the results deliver stable values which furthermore match the experimental results of lift and drag forces obtained from the wind-tunnel tests (e.g. $C_{D \text { EXP }}=0.0698$ and $C_{D, \text { CFD }}=0.0725$ for the drag coefficients of cupped wing model geometry). For determining the lift and drag coefficients we used the top-view projection area (see Table 1) as the reference of the falcon model. Thus, the evaluated numerical simulation model is used for the following investigations.

The numerical flow simulation was performed using the open source CFD software OpenFOAM (OpenCFD Ltd., Bracknell, UK). The code numerically solves the conservation equations of mass and momentum by means of a finite volume approach. The Reynolds number Re based on the length $L_{\mathrm{ref}}=400 \mathrm{~mm}$ reaches values of about $\operatorname{Re}=587000$ for $u=22.5 \mathrm{~m} / \mathrm{s}$. Therefore, turbulent flow is taken into account by a Reynolds averaged approach and the one equation Spalart-Almaras turbulence model. The turbulent viscosity $v_{T}$ for the Spalart-Almaras model can be determined by:

$$
\tilde{v}_{T}=\sqrt{\frac{3}{2}} u \cdot I \cdot l
$$

where $u$ is the free stream velocity, $I$ is the turbulence intensity ( $I=0.04 \%$, from experiments [18]) and $l$ is the length scale $\left(l=0.07 L_{\text {ref }}\right)$. The comparison with the results gained from the two equations $k-\omega$ SST model showed that the Spalart-Almaras simulations delivered more stable results. A major advantage of this model is that it was developed for flow simulations around an airfoil including wake regions and stall phenomena. Air was treated as a single-phase, incompressible $(M a=0.07)$, isothermal $\left(20^{\circ} \mathrm{C}\right)$ Newtonian fluid with constant density $\left(1.189 \mathrm{~kg} / \mathrm{m}^{3}\right)$ and viscosity $\left(18.232 \times 10^{-6} \mathrm{Pas}\right)$. Boundary conditions were chosen in agreement with the experimental situation described in the section before and are defined in Table 2. 


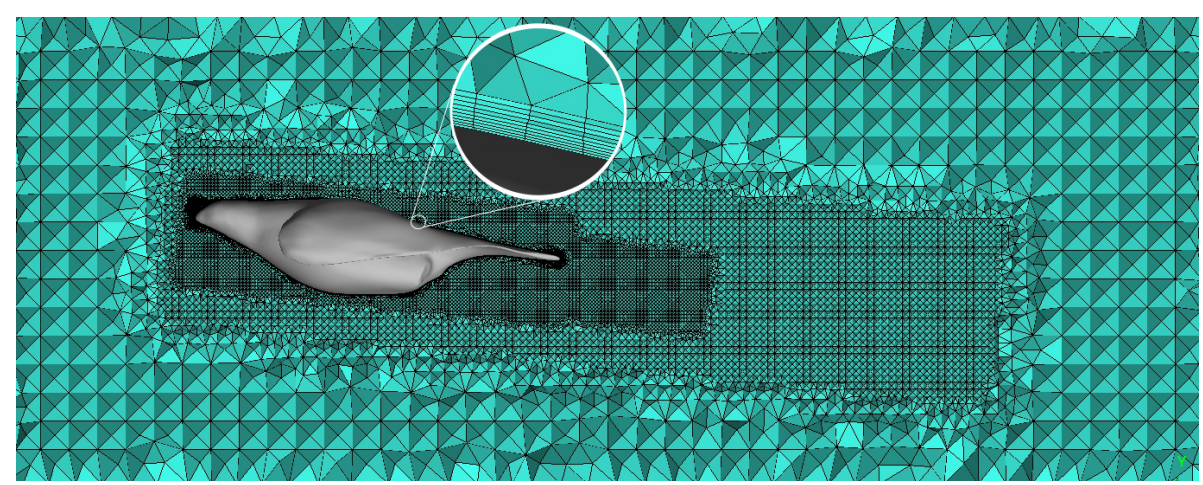

Figure 5. Prisms layer and density boxes of the grid refinement.

Table 2. Overview of boundary conditions.

\begin{tabular}{cccc}
\hline & & Flow variables & \\
Boundary & $\boldsymbol{u}$ & $\boldsymbol{p}$ & $\tilde{\boldsymbol{v}}_{\boldsymbol{T}}$ \\
\cline { 2 - 4 } Falcon & $\boldsymbol{u}=0$ & $\boldsymbol{n} \cdot \nabla p=0$ & $\tilde{\boldsymbol{v}}_{T}=0$ \\
Inlet & $22.5 \mathrm{~m} / \mathrm{s}$ & $\boldsymbol{n} \cdot \nabla p=0$ & $3.08 \times 10^{-4} \mathrm{~m}^{2} / \mathrm{s}$ \\
Outlet & $\boldsymbol{n} \cdot \nabla \boldsymbol{u}=0$ & $1013 \times 10^{3} \mathrm{~Pa}$ & $\boldsymbol{n} \cdot \nabla \tilde{\boldsymbol{v}}_{T}=0$ \\
Sides & Symmetry & Symmetry & Symmetry \\
\hline
\end{tabular}

Due to the incompressible character of the fluid, the pressure was set in average constant in the outlet of the test compartment, so that the simulated relative pressure field can be transferred in the post-processing to the correct pressure level with the help of experimental measurements. The simulations were carried out for steady flow conditions.

\section{Results}

The angle of attack for the investigated flight situation was determined in a previous study by Ponitz et al. (2014) [18] for the equilibrium condition at the maximum diving speed and is set to $\alpha=5^{\circ}$. Figure 6 shows a schematic vector diagram of the acting lift and drag forces on the falcon as well as the angle of attack in relation to the reference line of the falcon model which is built between the falcons tip and tail. The tip of the falcon is defined as the origin of the coordinate system (e.g. $x=0 \mathrm{~m})$.

Results from the numerical simulation are post-processed with the software packages ParaView 4.0.1 (Kitware Inc., Clifton Park, NY, USA) and Tecplot 3602013 (Tecplot Inc., Bellevue, WA, USA). Thus, the integral forces such as lift and drag forces are calculated from the velocity and pressure data field and visualizations are realized. With the calculated lift $(L)$ and drag $(D)$ forces the associated coefficients could be determined as followed:

$$
C_{L}=\frac{L}{q \cdot A}=\frac{2 \cdot L}{\rho \cdot u^{2} \cdot A}
$$

and

$$
C_{D}=\frac{D}{q \cdot A}=\frac{2 \cdot D}{\rho \cdot u^{2} \cdot A},
$$

where $q$ is the dynamic pressure, $\rho$ is the mass density of the fluid, $u$ is the free stream velocity and $A$ is the reference area of the wing, in both cases the top-view projection area $A_{\text {ref,top }}$.

All results are illustrated as comparative data between both configurations, the opened wing shape and the cupped wing shape. Table 3 shows the obtained lift and drag coefficients. Figure 7 shows the visualizations 


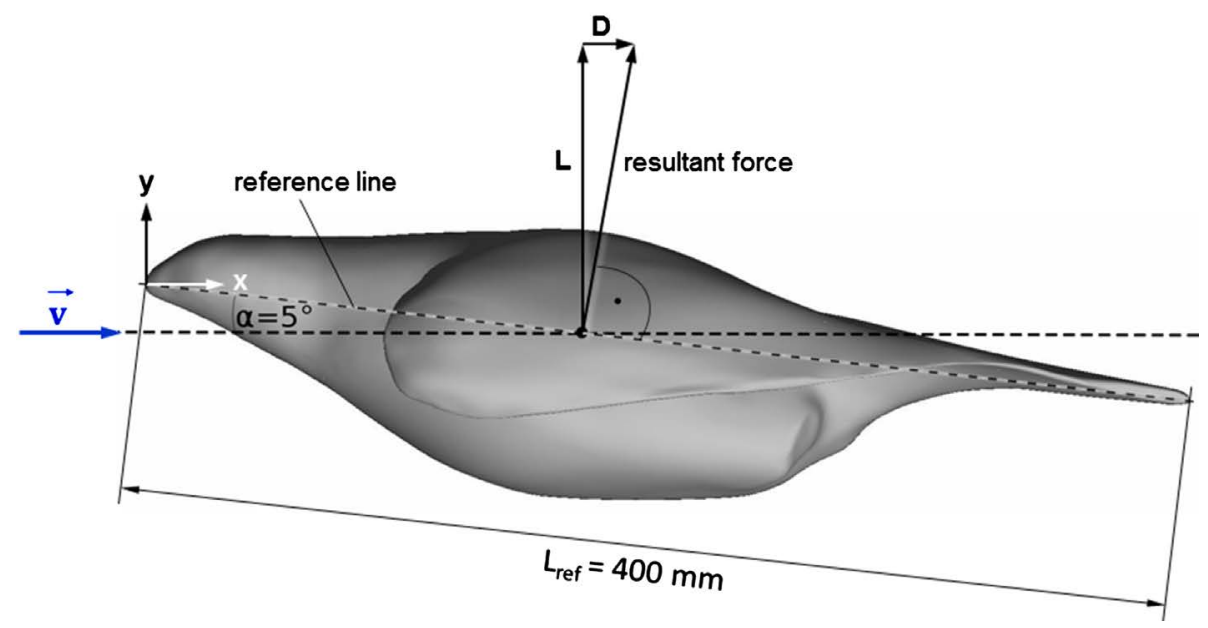

Figure 6. Definition of reference line, angle of attack and schematic vector diagram of forces.

Table 3. Comparison of lift and drag coefficients for both body geometries: opened wings vs. cupped wings (Reference area is the top-view projection area).

\begin{tabular}{ccc}
\hline \multirow{2}{*}{ Flow parameter } & \multicolumn{2}{c}{ Falcon model configuration } \\
\cline { 2 - 3 } & Opened wings & Cupped wings \\
\hline Lift coefficient $C_{L}$ & 0.0851 & 0.1119 \\
Drag coefficent $C_{D}$ & 0.0892 & 0.0725 \\
\hline
\end{tabular}

between the two configurations for surface pressure distribution, wall shear stress, streamlines below the wings, wake flow via $\lambda_{2}$ vortex detection criterion [19] and slices in the wake [20]. In addition, Figure 8 gives a more detailed insight of the surface streamlines on both body configurations.

The comparison of the lift coefficients (Table 3) shows a value of $C_{L, \text { opened }}=0.0851$ for the configuration with opened wings and a value of $C_{L, \text { cupped }}=0.1119$ for the cupped wing shape. The cupped wing profile causes an increased lift coefficient for identical simulation parameters. This is due to the cupped wings which deliver more wing area for lift. The passing air flow is held below the wing on the pressure side of the cupped wing. Hence, the acting lift component is increased in relation to the geometry of opened wing configuration. More interesting is the focus on the drag coefficient. Due to the extended cupped wing shape an increased drag coefficient is expected in relation to the opened wing geometry, however the results show the contrarian. With the cupped wings extension the drag coefficient is reduced from $C_{D \text {,opened }}=0.0892$ down to a value of $C_{D \text {,cupped }}=0.0725$, see Table 3 . The reason could be found in the flow details as discussed below by means of streamlines and near-surface flow visualizations.

For comparison with bluff body aerodynamics we calculated in addition the drag coefficient with the projection area along the axis of flight (frontal projection area $A_{\text {ref,front }}$ ). The following values were determined: $C_{D, \text { opened,frontal }}=0.2980$ and $C_{D, \text { cupped,frontal }}=0.2402$. They show the same tendency of decreased drag in the cupped wing configuration.

In the upper part of Figure 7 surface pressure distributions show typical areas of higher pressure on the tip of the falcon body and on the leading edge of the wings. Typical areas of lower pressure are found on the suction side of both wing configuration and especially between the cupped wings and the falcon body. In addition, wall shear stress distributions combined with the Line-Integral-Convolution (LIC) visualization method [21] show characteristic patterns of a streamlined body. Besides the visualizations of surface pressure and wall shear stress distributions, the streamlines and wake flow characteristics below and behind the falcon models show significant flow features (see middle and lower part of Figure 7). For instance, the comparison of the streamlines below the wings (color coded with the velocity magnitude) show different pathways and various hotspots of maximum velocity values below the wings. Streamlines around the opened wing configuration indicates flow separation whereas the cupped wings show streamlines which lies close to the body contour for a much longer distance 


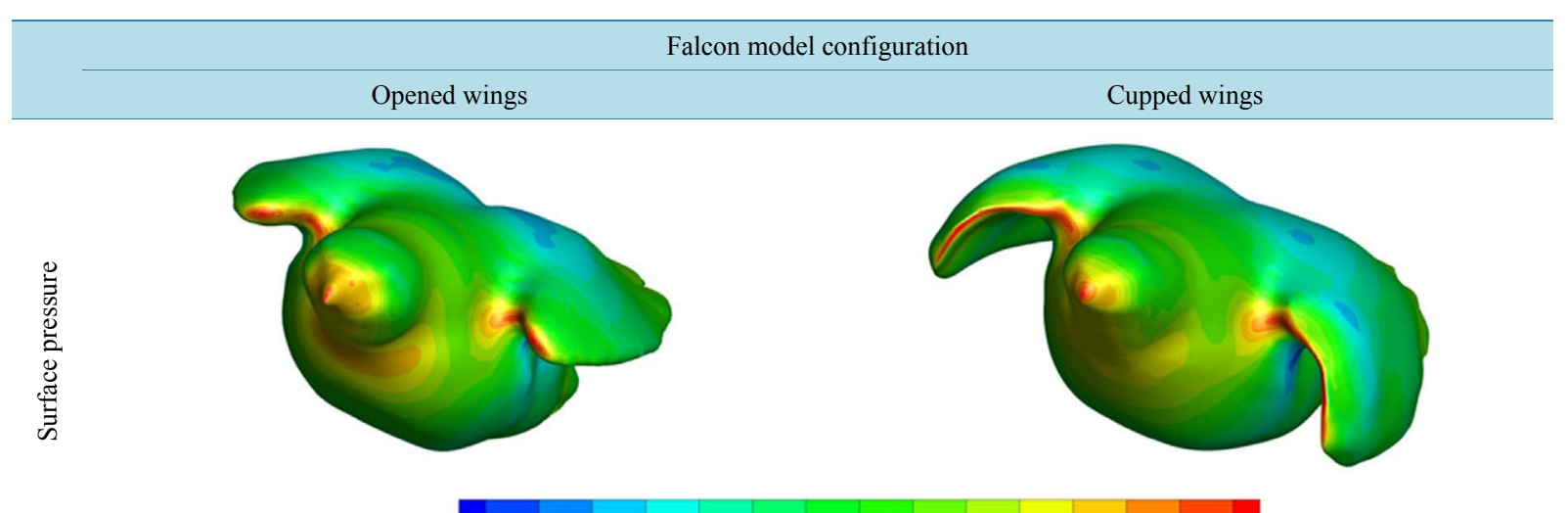

rel. pressure [Pa]: :-400-350 -300 -250 -200 -150 -100 $-50 \quad 0 \quad 50 \quad 100150200250300$

$\bar{\Xi}$
0
$\exists$
0
$\Xi$
0
0
0
0
$\vdots$
$\vdots$
0
$\overline{0}$
$\bar{\Xi}$
3
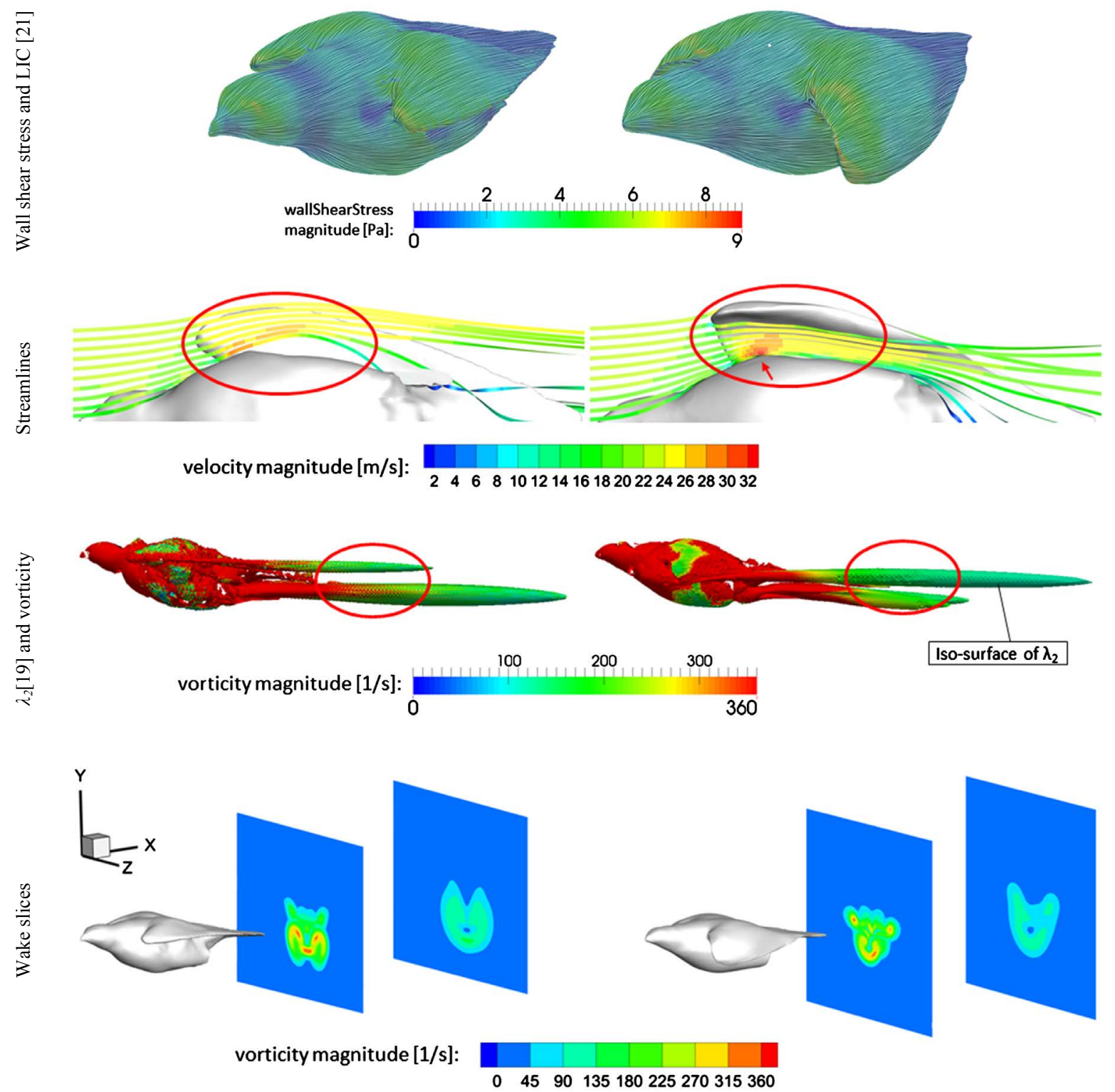

Figure 7. Comparison of visualized flow parameters for both configurations: opened wings vs. cupped wings. 
downstream. Additionally, the spot of higher velocity magnitude below the cupped wings indicate an acceleration of the flow in this region like in a tapering nozzle. Therefore the flow remains attached to the body for a longer distance downstream, which affects the body drag in a beneficial way. This could be one reason for the reduced drag of the cupped wing geometry in relation to the opened wing shape.

Furthermore, the wake flow behind the model visualized by the $\lambda_{2}$ vortex detection criterion (iso-surface is color coded with the vorticity magnitude) let recognize some differences between both configurations. In both cases two vortex pairs are recognizable. One vortex pair is generated around the wings (known as the wing-tip vortex) and one vortex pair is generated from flow separation at the aft part of the falcon main body (called herein the body vortex). The vorticity distribution in the wake is shown for two discrete slices in the Trefftzplane [20] at the positions close to $(x=0.5 \mathrm{~m})$ and far behind $(x=0.85 \mathrm{~m})$ the falcon model. The cupped wings lead to wing-tip vortices which are located further down in vertical direction than in the case of the opened wing configuration. Body vortices of both model shapes occur rather in the same location. Hence, the spatial arrangement of the vortex pairs (wing-tip and body vortices) is significantly closer in the case of the cupped wings geometry. In general, the induced drag of a wing depends on the strength of circulation and the lateral position of the wake vortices away from the centerline, thus it is concluded that the observed differences also influence the induced drag for both geometries.

Figure 8 depicts details of the surface streamlines around both body configurations. Streamlines below the opened wings indicates more clearly local flow separation in relation to the geometry with cupped wings where streamlines appear more continuous such as in an attached flow.

Figure 9 illustrates the three-dimensional arrangement of wake vortices visualized by the iso-surface of the vortex detection criterion $\lambda_{2}$ colored coded with the vorticity magnitude. The velocity distribution in the slice at position $x=0.64 \mathrm{~m}$ shows the downwash in the wake region of the falcon.

\section{Discussion and Conclusions}

This study investigated in detail the aerodynamics of steady flight conditions of a peregrine falcon in dive motion. The contours of body and wing shape as well as the dive speed and angle of attack have been detected in a previous study and were used herein for numerical flow simulations around the body and in the wake: we simulated the flow at an angle of attack of $5^{\circ}$ and a flow speed of $22.5 \mathrm{~m} / \mathrm{s}$.

The focus of this study was the comparison of the opened wing shape and geometry with cupped extension of the wing tip. The formulation "cupped wings" was first used by [9] to describe the shape of the downward tilted tips of the wing which is a typical falcon shape during dive. When comparing both wing configurations the results clearly reveal that the cupped wing configuration increases lift and decreases drag under the same flow conditions (and angle of attack). Although the total surface area in the cupped wing configuration is larger, the body drag is reduced. The reason therefore is the acceleration of the flow close to the body in the gap between cupped wing tip and main body surface. Therefore flow separation is shifted towards the trailing edge of the
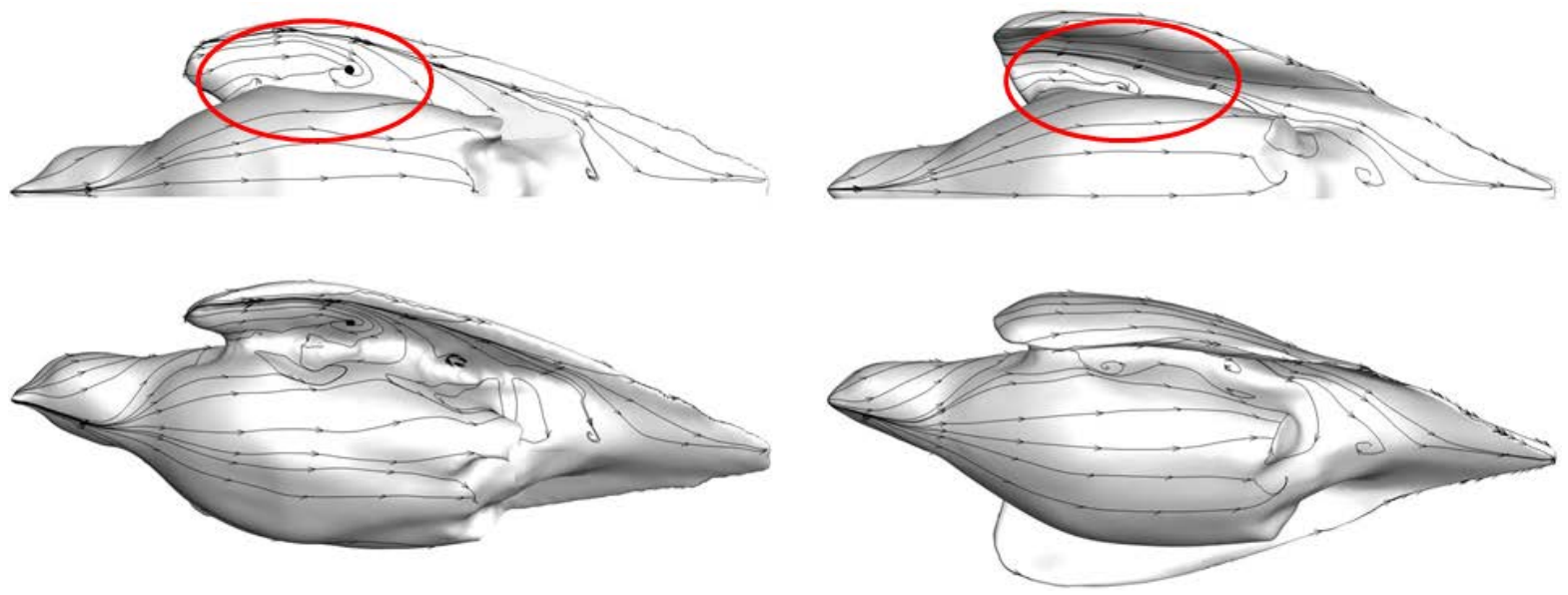

Figure 8. Comparison of visualized surface streamlines for both configurations: opened wings (left) vs. cupped wings (right). 


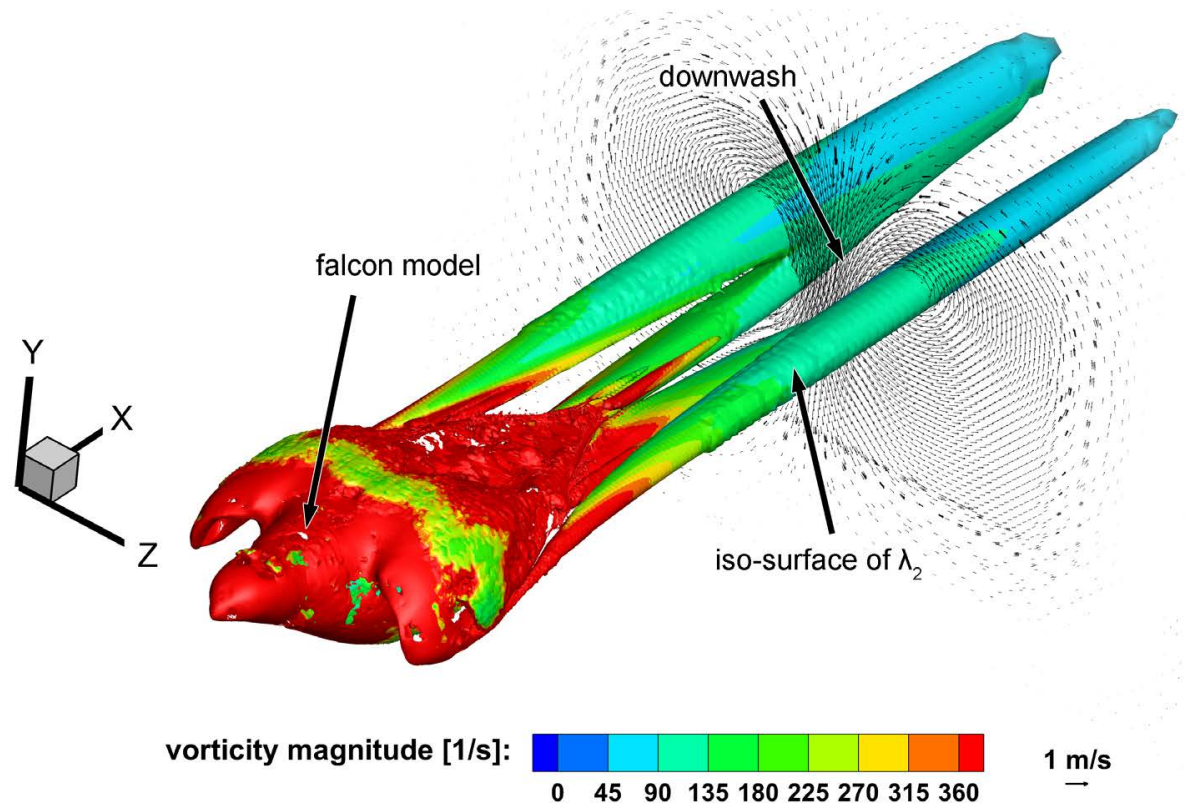

Figure 9. Three-dimensional visualization of the spatial arrangement of wake vortices. The iso-surface of $\lambda_{2}$ criterion is color coded with the vorticity magnitude.

body which reduces the form drag of the body. In addition, the modification of the tip vortices position and strength in the wake of the cupped wings hints on the beneficial effect on reducing the induced drag. This can be deduced from the analysis of the flow in the Trefftz-plane behind the body. This shows how fine the bird can tune the body forces by morphing the wing shape in diving flight conditions.

Conclusions drawn herein are based on a smooth surface of the model. In nature the body is covered with feathers which may also play a role [22]. The tiny scales and the elastic properties of the feathers were not taken into account. This is subject of ongoing work.

\section{Acknowledgements}

The study is funded by the Deutsche Forschungsgemeinschaft (BL 242/19-1; BR 1494/21-1). The funders had no role in study design, data collection and analysis, decision to publish, or preparation of the manuscript. We thank Horst Bleckmann for his support in gathering the data of the cupped wing model.

\section{References}

[1] del Hoyo, J., Elliott, A., Sargatal, J. and Collar, N.J. (1999) Handbook of the Birds of the World. Vol. 5, Lynx Edicions, Barcelona.

[2] Podbregar, N. (2013) Das Geheimnis des Fliegens-Tierischen Flugkünstlern auf der Spur: Strategien der Evolution. Springer, Berlin and Heidelberg, 227-243.

[3] Tucker, V.A. and Parrott, G.C. (1970) Aerodynamics of Gliding Flight in a Falcon and Other Birds. Journal of Experimental Biology, 52, 345-367.

[4] Orton, D.A. (1975) The Speed of a Peregrine's Dive. The Field, 588-590.

[5] Brown, L.A. (1976) British Birds of Prey. Collins, London.

[6] Alerstam, T. (1987) Radar Observations of the Stoop of the Peregrine Falcon Falco Peregrinus and the Goshawk Accipiter Gentilis. Ibis, 129, 267-273. http://dx.doi.org/10.1111/j.1474-919X.1987.tb03207.x

[7] Savage, C. (1992) Peregrine Falcons. Sierra Club, San Francisco.

[8] Clark, W.S. (1995) How Fast Is the Fastest Bird? WildBird, 9, 42-43.

[9] Tucker, V.A. (1998) Gliding Flight: Speed and Acceleration of Ideal Falcons during Diving and Pull Out. Journal of Experimental Biology, 201, 403-414.

[10] Franklin, D.C. (1999) Evidence of Disarray amongst Granivorous Bird Assemblages in the Savannas of Northern Aus- 
tralia, a Region of Sparse Human Settlement. Biological Conservation, 90, 53-68. http://dx.doi.org/10.1016/S0006-3207(99)00010-5

[11] Nachtigall, W. (1975) Vogelflügel und Gleitflug Einführung in die aerodynamische Betrachtungsweise des Flügels. Journal für Ornithologie, 116, 1-38. http://dx.doi.org/10.1007/BF01643073

[12] Nachtigall, W. (1998) Der Gleitflug von Vögeln. Physik in unserer Zeit, 1, 25-29.

[13] Lentink, D., Müller, U.K., Stamhuis, E.J., de Kat, R., van Gestel, W., Veldhuis, L.L.M., et al. (2007) How Swifts Control Their Glide Performance with Morphing Wings. Nature, 446, 1082-1085. http://dx.doi.org/10.1038/nature05733

[14] Ratcliffe, D.A. (1980) The Peregrine Falcon. Buteo Books, Vermillion.

[15] Hustler, K. (1983) Breeding Biology of the Peregrine Falcon in Zimbabwe. Ostrich, 54, 161-171. http://dx.doi.org/10.1080/00306525.1983.9634466

[16] Tucker, V.A. (1990) Body Drag, Feathers Drag and Interference Drag of the Mounting Strut in a Peregrine Falcon, Falco peregrinus. Journal of Experimental Biology, 149, 449-468.

[17] Seitz, K. (1999) Vertical Flight. NAFA Journal, 38, 68-72.

[18] Ponitz, B., Schmitz, A., Fischer, D., Bleckmann, H. and Brücker, C. (2014) Diving-Flight Aerodynamics of a Peregrine Falcon (Falco peregrinus). PLoS ONE, 9, e86506. http://dx.doi.org/10.1371/journal.pone.0086506

[19] Jeong, J. and Hussain, F. (1995) On the Identification of a Vortex. Journal of Fluid Mechanics, 285, 69-94. http://dx.doi.org/10.1017/S0022112095000462

[20] Krasny, R. (1987) Computation of Vortex Sheet Roll-Up in the Trefftz Plane. Journal of Fluid Mechanics, 184, 123155. http://dx.doi.org/10.1017/S0022112087002830

[21] Cabral, B. and Leedom, L.C. (1993) Imaging Vector Fields Using Line Integral Convolution. In: Proceedings of ACM SIGGRAPH'93, Anaheim, 2-6 August 1993, 263-270.

[22] Schmitz, A., Ponitz, B., Brücker, C., Schmitz, H., Herweg, J. and Bleckmann, H. (2014) Morphological Properties of the Last Primaries, the Tail Feathers, and the Alulae of Accipiter nisus, Columba livia, Falco peregrinus, and Falco tinnunculus. Journal of Morphology, Early View. http://dx.doi.org/10.1002/jmor.20317

\section{Nomenclature}

$\begin{array}{ll}\alpha & \left.\text { angle of attack [ }{ }^{\circ}\right] \\ A_{\text {ref }} & \text { reference area of the wing }\left[\mathrm{m}^{2}\right] \\ C_{D} & \text { drag coefficient [-] } \\ C_{L} & \text { lift coefficient [-] } \\ D & \text { drag force [N] } \\ I & \text { turbulence intensity [\%] } \\ L & \text { lift force [N] } \\ \lambda_{2} & \text { vortex detection criterion }\left[\mathrm{s}^{-1}\right] \\ l & \text { length scale for Spalart-Almaras [m] } \\ L_{\text {ref }} & \text { reference length of the model [m] } \\ M a & \text { Mach number [-] } \\ p & \text { pressure [Pa] }\end{array}$

$q \quad$ dynamic pressure $[\mathrm{Pa}]$

$\rho \quad$ mass density of the fluid $\left[\mathrm{kg} \cdot \mathrm{m}^{-3}\right]$

Re Reynolds number [-]

$u, v \quad$ free stream velocity $\left[\mathrm{m} \cdot \mathrm{s}^{-1}\right]$

$v_{T} \quad$ kinematic viscosity $\left[\mathrm{m}^{2} \cdot \mathrm{s}^{-1}\right]$

$x \quad$ coordinate in flow direction [m]

$y^{+} \quad$ dimensionless wall distance [-]

CAD computer aided design

CFD computational fluid dynamics

LIC line integral convolution

PVC polyvinyl chloride 
Scientific Research Publishing (SCIRP) is one of the largest Open Access journal publishers. It is currently publishing more than 200 open access, online, peer-reviewed journals covering a wide range of academic disciplines. SCIRP serves the worldwide academic communities and contributes to the progress and application of science with its publication.

Other selected journals from SCIRP are listed as below. Submit your manuscript to us via either submit@scirp.org or Online Submission Portal.
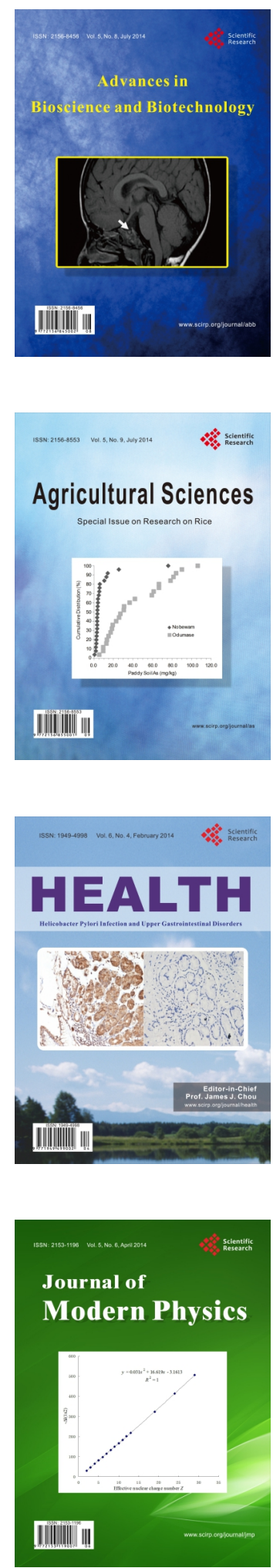
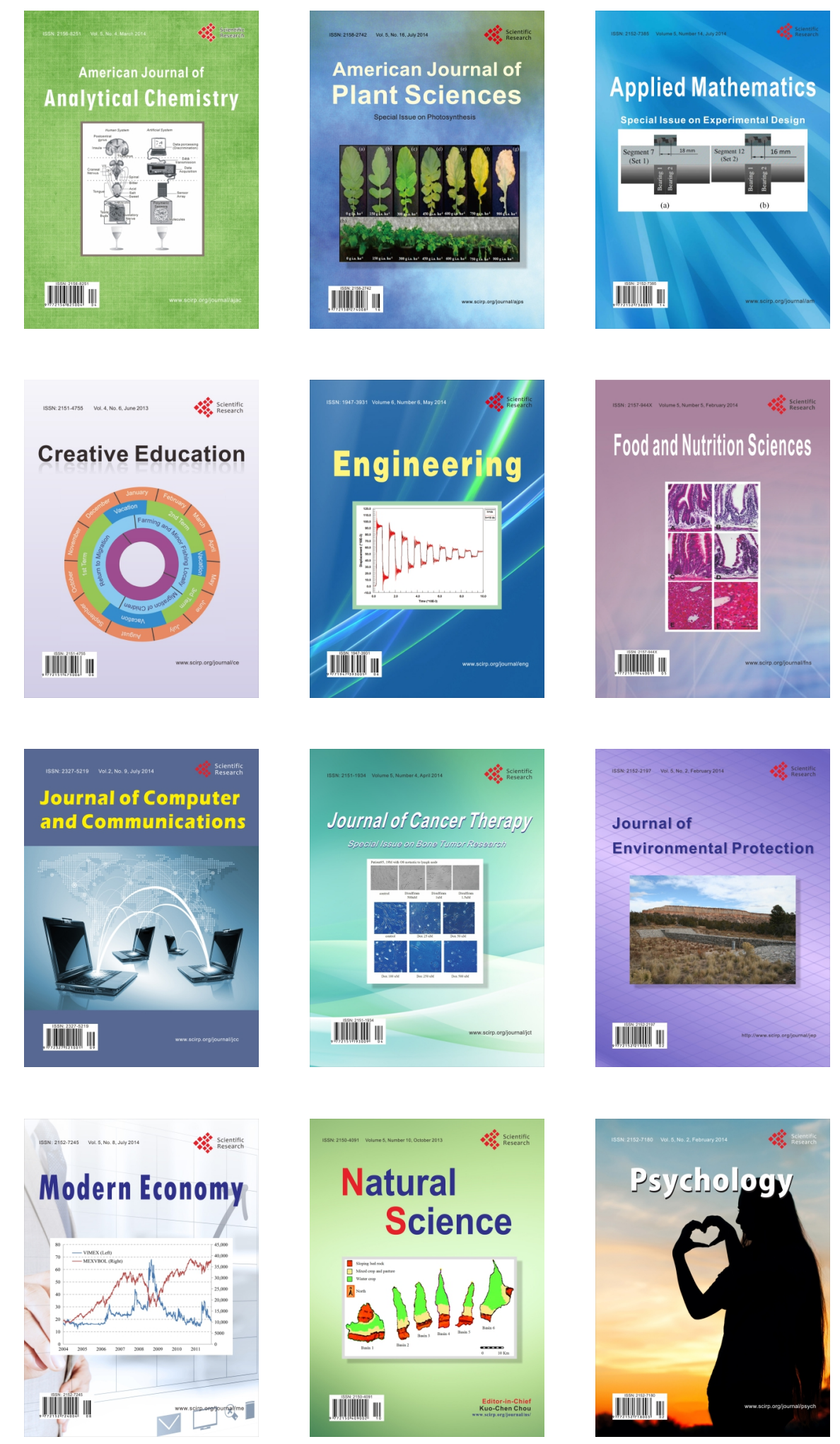